\title{
Pentafluorophenylammonium triflate- $\mathrm{CuCl}_{2}$ : A mild, efficient and reusable heterogeneous catalyst system for facile synthesis of 4(3H)-quinazolinones under solvent-free conditions
}

\author{
NASER MONTAZERI*, KHALIL POURSHAMSIAN, SOGHRA YOSEFIYAN and \\ SEYDEH SAMANEH MOMENI \\ Department of Chemistry, Tonekabon Branch, Islamic Azad University, Tonekabon 46819-89711, Iran \\ e-mail: montazer50@toniau.ac.ir
}

MS received 9 September 2011; revised 10 December 2011; accepted 11 January 2012

\begin{abstract}
Pentafluorophenylammonium triflate (PFPAT) was found to be highly efficient, and recyclable heterogeneous catalyst for the synthesis of $4(3 \mathrm{H})$-quinazolinones by cyclocondensation reaction of 2aminobenzamide with aryl aldehydes in the presence of $\mathrm{CuCl}_{2}$ as co-catalyst in good to excellent yields under solvent-free conditions. The present methodology offers several advantages, such as simple procedure with an easy work-up, high yields, short reaction times, and the absence of any volatile or hazardous organic solvents. Moreover, the catalyst can be easily recovered and reused at least three times with only slight reduction in its catalytic activity.
\end{abstract}

Keywords. Pentafluorophenylammonium triflate; heterogeneous catalysis; $4(3 \mathrm{H})$-quinazolinones; solvent-free conditions.

\section{Introduction}

4(3H)-quinazolinones are an important class of fused heterocycles with a wide range of pharmacological and biological activities such as antagonist, ${ }^{1}$ antimalarial, ${ }^{2}$ antitumour, ${ }^{3}$ antibacterial, ${ }^{4}$ anti-inflammatory, ${ }^{5}$ insecticidal, and antimicrobial activity. ${ }^{6}$ In addition, quinazolinone moiety is a building block for approximately 150 naturally occurring alkaloids, such as glycosminine,${ }^{7}$ deoxyvasicinone,${ }^{8}$ and drugs like methaqualone ${ }^{9}$ and piriqualone. ${ }^{10}$ Also, a small number of quinazolinones have been reported as potent chemotherapeutic agents in the treatment of tuberculosis. ${ }^{11}$ There are several methods for the synthesis of $4(3 \mathrm{H})$-quinazolinones using DDQ/DMF, ${ }^{12} \mathrm{Ga}(\mathrm{OTf})_{3},{ }^{13} \mathrm{Yb}(\mathrm{OTf})_{3},{ }^{14} \mathrm{I}_{2 /} \mathrm{KI},{ }^{15}$ TBAB $,{ }^{16} \mathrm{Sc}(\mathrm{OTf})_{3},{ }^{17} \mathrm{P}$-toluenesulphunic acid/DDQ, ${ }^{18}$ $\mathrm{NaHSO}_{3},{ }^{19}$ and $\mathrm{SnCl}_{4} \cdot 4 \mathrm{H}_{2} \mathrm{O},{ }^{20}$ as catalysts. However, most of these procedures have significant drawbacks such as long reaction times, low yields of the products, harsh reaction conditions, and difficult work-up. Therefore, the development of simple, efficient, clean, high-yielding, and environmentally friendly approaches using new catalysts for the synthesis of these compounds is an important task for organic chemists.

The development of heterogeneous catalysts for organic synthesis has become a major area of research.

*For correspondence
The potential advantages of these materials over homogeneous systems could lead to novel, environmentally benign chemical procedures for academia and industry. ${ }^{21-23}$ Application of solid acids in organic transformations is important because they have many advantages including ease of products separation, recycling of the catalyst and environmental acceptability as compared to liquid acid catalysts. ${ }^{24,25}$

Recently, Tanabe et al. reported the application of pentafluorophenylammonium triflate $\left(\mathrm{C}_{6} \mathrm{~F}_{5} \mathrm{NH}_{3} \mathrm{OTf}\right.$; PFPAT) as a novel heterogeneous catalyst in organic transformation such as esterification of carboxylic acids with alcohols, ${ }^{26} \mathrm{C}$-acylations of enol silyl ethers or ketene silyl (thio)acetals with acid chlorides ${ }^{27}$ and Mukaiyama aldol and Mannich reactions using ketene silyl acetals with ketones and oxime ethers. ${ }^{28}$ However, to the best of our knowledge there are no examples on the use of PFPAT as catalyst for the synthesis of $4(3 \mathrm{H})$-quinazolinones.

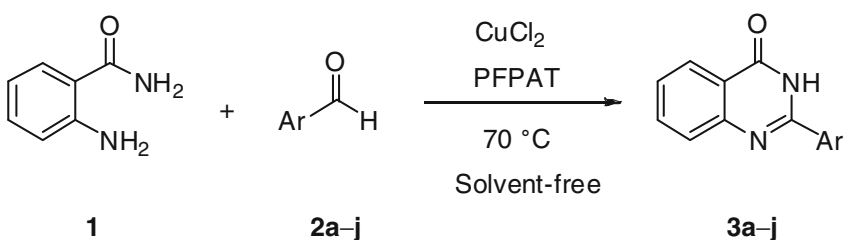

Scheme 1. Synthesis of $4(3 \mathrm{H})$-quinazolinones catalysed by PFPAT. 
Prompted by these findings and due to our interest in the synthesis of heterocyclic compounds, ${ }^{29-32}$ and in continuation of our previous works on the applications of reusable catalysts in organic reactions, ${ }^{33-35}$ we report here an efficient synthesis of $4(3 \mathrm{H})$-quinazolinones by cyclocondensation reaction of 2-aminobenzamide with aryl aldehydes using PFPAT as a solid acid catalyst (scheme 1).

\section{Experimental}

All chemicals were available commercially and used without additional purification. The catalyst was synthesized according to the literature. ${ }^{26}$ Melting points were recorded on an electrothermal type 9100 melting point apparatus. The IR spectra were obtained using a 4300 Shimadzu spectrophotometer in $\mathrm{KBr}$ disks. The ${ }^{1} \mathrm{H}$ NMR (500 MHz) spectra were recorded with a Bruker DRX500 spectrometers.

\subsection{Preparation of the catalyst (PFPAT)}

To a solution of 2,3,4,5,6-pentafluoroaniline ( $25 \mathrm{mmol})$ in toluene $(25 \mathrm{~mL}), \mathrm{CF}_{3} \mathrm{SO}_{3} \mathrm{H}(25 \mathrm{mmol})$ was added at $0-5^{\circ} \mathrm{C}$. The reaction mixture was stirred at the same temperature for $30 \mathrm{~min}$. After this time, the solvent was evaporated in vacuo, the crude product was collected and washed with hexane to give the pure catalyst in $92 \%$ yield. ${ }^{26}$

\subsection{General procedure for the synthesis of 4(3H)- quinazolinones $\mathbf{3 a - j}$ catalysed by PFPAT}

A mixture of 2-aminobenzamide ( $1 \mathrm{mmol})$, an aromatic aldehyde $(1 \mathrm{mmol})$ and $\mathrm{CuCl}_{2}(0.4 \mathrm{mmol})$ in the presence of PFPAT $(0.25 \mathrm{mmol})$ as catalyst was heated on the oil bath at $70^{\circ} \mathrm{C}$ for $60-120 \mathrm{~min}$. The reaction was monitored by thin-layer chromatography (TLC). After completion of the reaction, the reaction mixture was cooled to room temperature and then water was added. The precipitate was filtered off and recrystallized from ethanol to give compounds $\mathbf{3 a}-\mathbf{j}$ in high yields.

\subsection{Recycling and reusing of the catalyst}

The catalyst is soluble in water and could therefore be recycled as the filtrate. The catalyst was recovered by evaporation of the water, washed with hexane, dried at $50^{\circ} \mathrm{C}$ under vacuum for $1 \mathrm{~h}$ and reused in another reaction without appreciable reduction in the catalytic activity.
Table 1. Effect of PFPAT amount and temparature on the model reaction. ${ }^{\mathrm{a}}$

\begin{tabular}{lcccc}
\hline Entry & Catalyst $(\mathrm{mol} \%)$ & $\mathrm{T}\left({ }^{\circ} \mathrm{C}\right)$ & Time $(\min )$ & Yield $(\%)^{\mathrm{b}}$ \\
\hline 1 & None & 70 & 120 & None \\
2 & 25 & r.t & 120 & None \\
3 & 10 & 70 & 300 & 17 \\
4 & 15 & 70 & 120 & 28 \\
5 & 20 & 70 & 90 & 50 \\
6 & 20 & 80 & 60 & 47 \\
7 & 25 & 60 & 120 & 32 \\
8 & 25 & 70 & 60 & 86 \\
9 & 25 & 80 & 45 & 82 \\
10 & 30 & 60 & 120 & 46 \\
11 & 30 & 70 & 90 & 67 \\
12 & 30 & 80 & 60 & 62 \\
\hline
\end{tabular}

${ }^{a} 1 \mathrm{mmol} 2$-aminobenzamide, $1 \mathrm{mmol}$ benzaldehyde and $0.4 \mathrm{mmol} \mathrm{CuCl}_{2}$ under solvent-free conditions.

${ }^{\mathrm{b}}$ Isolated yields

\section{Results and discussion}

Solvent-free conditions are especially important for providing an eco-friendly system. The number of publications reporting solvent-free conditions for the heterocyclic synthesis has increased rapidly in recent years. ${ }^{36}$ One advantage of solvent-free reactions, in comparison to the reaction in molecular solvents, is that the compounds formed are often sufficiently pure to circumvent extensive purification using chromatography. Therefore, due to the increasing demand in modern organic processes for avoiding expensive purification, we decided to investigate the efficiency of PFPAT as catalyst in the synthesis of $4(3 \mathrm{H})$-quinazolinones under solvent-free conditions.

At first, the synthesis of compound 3a was selected as a model reaction to determine suitable reaction conditions. The reaction was carried out by heating a

Table 2. Synthesis of compound $\mathbf{3 a}$ in the presence of PFPAT in different solvents. ${ }^{\mathrm{a}}$

\begin{tabular}{lcccc}
\hline Entry & Solvent & $\mathrm{T}\left({ }^{\circ} \mathrm{C}\right)$ & Time $(\min )$ & Yield $(\%)^{\mathrm{b}}$ \\
\hline 1 & $\mathrm{EtOH}$ & Reflux & 120 & 40 \\
2 & $\mathrm{MeOH}$ & Reflux & 120 & 18 \\
3 & $\mathrm{CHCl}_{3}$ & Reflux & 120 & Trace \\
4 & $\mathrm{PhCH}_{3}$ & Reflux & 120 & Trace \\
5 & Solvent-free $^{7}$ & 70 & 60 & 86 \\
\hline
\end{tabular}

${ }^{a} 1 \mathrm{mmol} 2$-aminobenzamide, $1 \mathrm{mmol}$ benzaldehyde, $0.4 \mathrm{mmol}$ $\mathrm{CuCl}_{2}$, and $0.25 \mathrm{mmol}$ PFPAT under solvent-free conditions.

${ }^{\mathrm{b}}$ Isolated yields 
Table 3. PFPAT catalysed synthesis of $4(3 \mathrm{H})$-quinazolinones $\mathbf{3 a}-\mathbf{j} .{ }^{\mathrm{a}}$

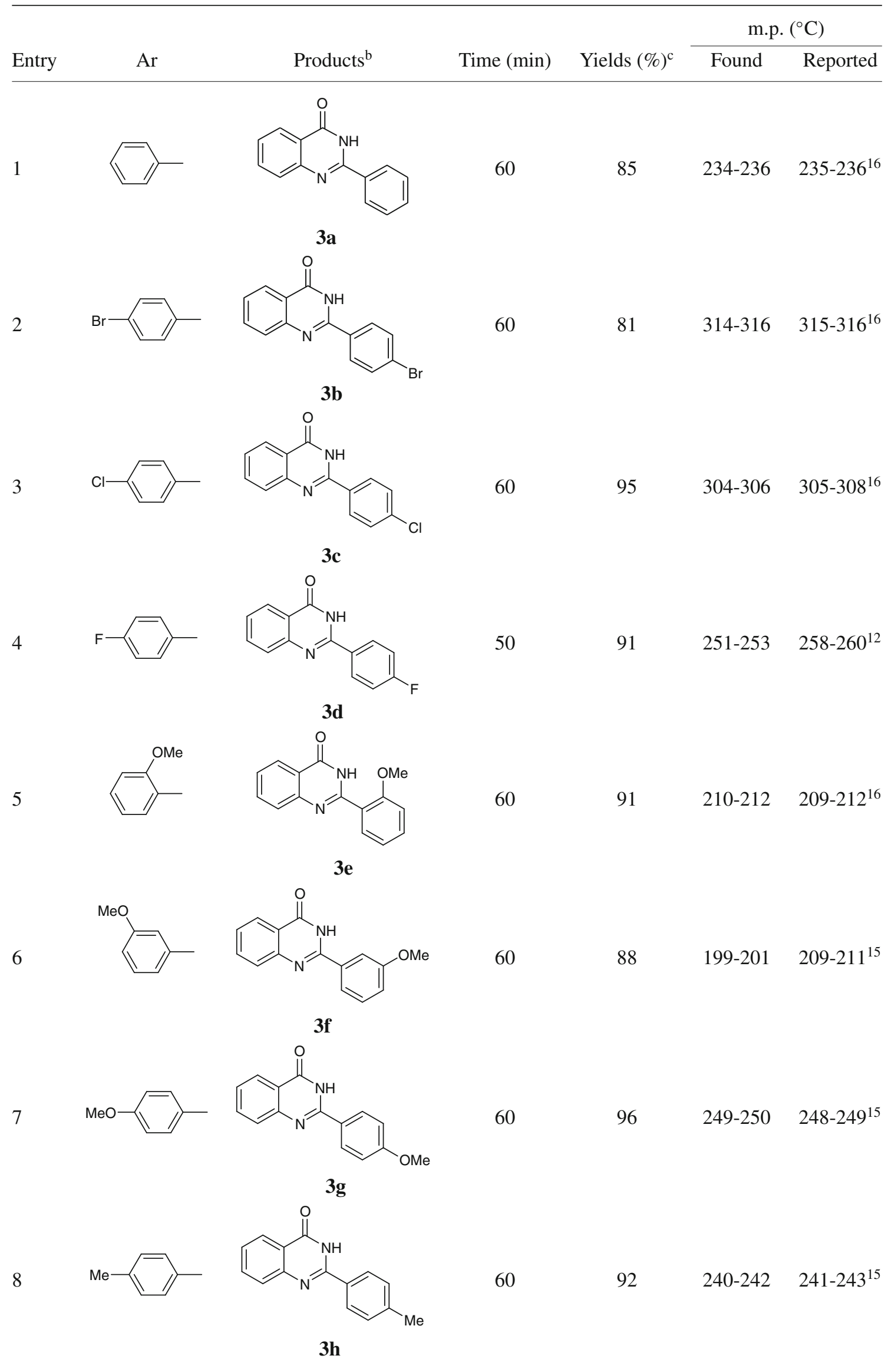


Table 3. (continued)

Entry $\quad$ Time (min) $\quad$ Yields $(\%)^{\mathrm{c}} \quad \begin{gathered}\text { m.p. }\left({ }^{\circ} \mathrm{C}\right) \\ \end{gathered}$

$3 \mathbf{j}$

\footnotetext{
${ }^{\mathrm{a}} 1 \mathrm{mmol}$ 2-aminobenzamide, $1 \mathrm{mmol}$ aryl aldehyde, $0.4 \mathrm{mmol} \mathrm{CuCl}_{2}$, and $0.25 \mathrm{mmol}$ PFPAT at $70^{\circ} \mathrm{C}$ under solvent-free conditions.

${ }^{\mathrm{b}}$ All the products were characterized by IR and ${ }^{1} \mathrm{H}$ NMR spectral data and comparision of their melting points with those of authentic samples.

${ }^{\mathrm{c}}$ Isolated yields
}

mixture of 2-aminobenzamide (1 mmol) and benzaldehyde $(1 \mathrm{mmol})$ in the presence of $\mathrm{CuCl}_{2}(0.4 \mathrm{mmol})$ under various amounts of PFPAT and solvent-free conditions at different temperatures (table 1). It was found that the yield of compound 3a was strongly affected by the catalyst amount and reaction temperature. No product was obtained in the absence of the catalyst PFPAT (entry 1 ) or in the presence of the catalyst at room temperature (entry 2) indicating that the catalyst and temperature are necessary for the reaction. Increasing the amount of the catalyst and reaction temperature up to $25 \mathrm{~mol} \%$ and $70^{\circ} \mathrm{C}$, respectively, increased the yield of the product 3a, whereas further increase in both catalyst amount and temperature was found to have an inhibitory effect on formation of the product (entries 9-12). Variation of the co-catalyst $\mathrm{CuCl}_{2}$ has no considerable effect on the conversion of starting materials, however the products are obtained contaminated with by-products when less than $40 \mathrm{~mol} \%$ of $\mathrm{CuCl}_{2}$ is used. In addition, increasing the amount of this catalyst to greater than $40 \mathrm{~mol} \%$ has no considerable effect on the purity and the yield of products. Therefore, we concluded that $\mathrm{CuCl}_{2}$ could play as an oxidation catalyst during dehydrogenation of the initially formed products.

Also, the reaction was carried out in various solvents (table 2). As shown in this table, the yield of the reaction under solvent-free conditions was greater and the reaction time was generally shorter than the conventional methods.
In order to evaluate the generality of this model reaction, we then prepared a range of $4(3 \mathrm{H})$-quinazolinones using several aromatic aldehydes under the optimized reaction conditions. In all cases, aromatic aldehydes with substituents carrying either electron-donating or electron-withdrawing groups reacted successfully and gave the expected products in excellent yields and short reaction times. The type of aldehyde had no significant effect on the reaction. The results are shown in table 3 .

Reusability of the catalyst was also investigated. For this purpose, the same model reaction was again studied under optimized conditions. After the completion of the reaction, the catalyst was recovered according to the procedure mentioned in experimental section

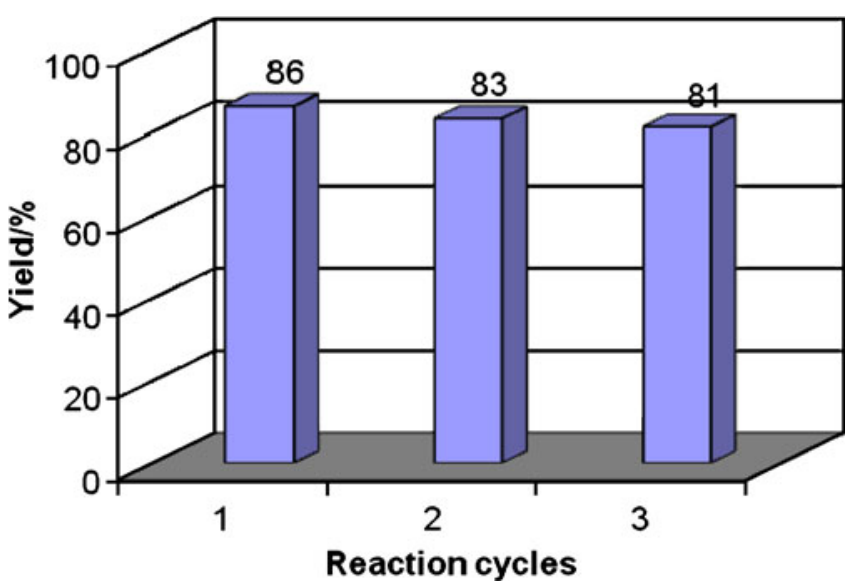

Figure 1. Reusability of PFPAT for model reaction. 
and reused for a similar reaction. As shown in figure 1, the catalyst could be used at least three times with only slight reduction in the catalytic activity.

In summary, a highly efficient, and green method for the synthesis of $4(3 \mathrm{H})$-quinazolinones by cyclocondensation reaction of 2-aminobenzamide with aryl aldehydes using PFPAT- $\mathrm{CuCl}_{2}$ as catalyst system in good to excellent yields under solvent-free conditions has been reported. Some attractive features of this protocol are high yields, simple procedure, easy work-up, high catalytic activity and recyclability and reusability of the catalyst. Also, it has all advantages devoted to solvent-free reactions namely environmentally friendly conditions.

\section{Acknowledgement}

The authors are thankful to Islamic Azad University, Tonekabon Branch for financial support.

\section{References}

1. Padia J K, Field M, Hinton J, Meecham K, Pablo J, Pinnock R, Roth B D, Singh L, Suman-Chauhan N, Trivedi B K and Webdale L 1998 J. Med. Chem. 411042

2. Takaya Y, Tasaka H, Chiba T, Uwai K, Tanitsu M A, Kim H S, Wataya Y, Miura M, Takeshita M and Oshima Y 1999 J. Med. Chem. 423163

3. Xia Y, Yang Z, Hour M, Kuo S, Xia P, Bastow K F, Nakanishi Y, Nampoothiri P, Hackl T, Hamel E and Lee K 2001 Bioorg. Med. Chem. Lett. 111193

4. Kung P P, Casper M D, Cook K L, Wilson-Lingard L, Risen L M, Vickers A, Ranken R, Blyn L B, Wyatt R, Cook P D and Ecker J 1999 J. Med. Chem. 424705

5. Yadav M R, Shirude S T, Parmar A, Balaraman R and Giridhar R 2006 Khim. Geterotsikl. Soedin. 1198.

6. Singh T, Sharma S, Srivastava V K and Kumar A 2006 Indian J. Chem. B: Org. Med. Chem. 452558

7. Kametani T, Loc C V, Higa T, Koizumi M, Ihara M and Fukumoto K J 1977 J. Am. Chem. Soc. 992306

8. Liu J-F, Ye P, Sprague K, Sargent K, Yohannes D, Baldino C M, Wilson C J and Ng S C 2005 Org. Lett. 7 3363

9. Chenard B L, Menniti F S, Pagnozzi M J, Shenk K D, Ewing F E and Welch W M 2000 Bioorg. Med. Chem. Lett. 101203

10. Wolfe J F, Rathman T L, Sleevi M C, Campbell J A and Greenwood T D 1990 J. Med Chem. 33161
11. Waisser K, Gregor J, Dostal H, Kunes J, Kubicova L, Klimesova V and Kaustova J 2001 Farmaco 56803

12. Bhat B A and Sahu D P 2004 Synth. Commun. 342169

13. Chen J, Wu D, He F, Liu M, Wu H, Ding J and Su W 2008 Tetrahedron Lett. 493814

14. Wang L, Xia J J, Qin F, Qian C T and Sun J 2003 Synthesis 81241

15. Bakavoli M, Shiri A, Ebrahimpour Z and Rahimizadeh M 2008 Chin. Chem. Lett. 191403

16. Davoodnia A, Allameh S, Fakhari A R and TavakoliHoseini N 2010 Chin. Chem. Lett. 21550

17. Chen J X, Wu H Y and Su W K 2007 Chin. Chem. Lett. 18536

18. Naleway J J, Fox C M J, Robinhold D, Terpetsching E, Olsen N A and Haugland R P 1994 Tetrahedron Lett. 35 8569

19. Lopez S E, Rosales M E, Urdaneta N, Godoy M V and Charris J E 2000 J. Chem. Res. Synop. 6258

20. Oskooie H A, Baghernezhad B and Heravi M M 2007 Indian J. Heterocycl. Chem. 1795

21. Song C E, Lim J S, Kim S C, Lee K and Chi D Y 2000 Chem. Commun. 2415 (and references cited therein)

22. Sheldon R A and Van Bekkum H 2002 Catalysis through heterogeneous catalysis, Germany: Wiley- $\mathrm{VCH}$, Weinheim, 61

23. Gerard V S and Notheisz F 2000 Heterogeneous catalysis in organic chemistry, San Diego, Calif: Elsevier

24. Okuhara T 2002 Chem. Rev 1023641

25. Davoodnia A, Tavakoli-Nishaburi A and TavakoliHoseini N 2011 Bull. Korean Chem. Soc. 32635

26. Funatomi T, Wakasugi K, Misaki T and Tanabe Y 2006 Green Chem. 81022

27. Iida A, Osada J, Nagase R, Misaki T and Tanabe Y 2007 Org. Lett. 91859

28. Nagase R, Osada J, Tamagaki H and Tanabe Y 2010 Adv. Synth. Catal. 3521128

29. Porshamsian K, Montazeri N, Rad-Moghadam K and Ali-Asgari S 2010 J. Heterocyl. Chem. 471439

30. Hatamjafari F and Montazeri N 2009 Turk. J. Chem. 33 797

31. Rad-Moghadam K and Montazeri N 2007 Asian J. Chem. 192467

32. Montazeri N and Rad-Moghadam K 2008 Chin. Chem. Lett. 191143

33. Montazeri N, Khaksar S, Nazari A, Alavi S S, Vahdat S M and Tajbakhsh M 2011 J. Fluorine Chem. 132450

34. Montazeri N 2010 Asian J. Chem. 227432

35. Rad-Moghadam K and Montazeri N 2009 Asian J. Chem. 21499

36. Martins M A P, Frizzo C P, Moreira D N, Buriol L and Machado P 2009 Chem. Rev. 1094140 